\title{
Do multiple community-based interventions on health promotion tackle health inequalities?
}

\author{
Stefan Nickel ${ }^{*}$ ib and Olaf von dem Knesebeck
}

\begin{abstract}
Background: Previous systematic reviews of the impact of multi-component community-based health promotion interventions on reducing health inequalities by socio-economic status (SES) were restricted to physical activity and smoking behavior, and revealed limited and rather disillusioning evidence. Therefore, we conducted a comprehensive review worldwide to close this gap, including a wide range of health outcomes.

Methods: The Pubmed and PsycINFO databases were screened for relevant articles published between January 1999 and August 2019, revealing 87 potentially eligible publications out of 2876 hits. In addition, three studies out of a prior review on the effectiveness of community-based interventions were reanalyzed under the new research question. After a systematic review process, 23 papers met the inclusion criteria and were included in the synthesis.

Results: More than half (56.5\%) of the studies reported improvements of socially disadvantaged communities overall (i.e. reduced inequalities at the area level) in at least one health behavior and/or health status outcome. Amongst the remaining studies we found some beneficial effects in the most deprived sub-groups of residents (8.2\%) and studies with no differences between intervention and control areas (34.8\%). There was no evidence that any program under review resulted in an increase in health disparity.

Conclusions: Our results confirm that community-based interventions may be reducing absolute health inequalities of deprived and disadvantaged populations, but their potential so far is not fully realized. For the future, greater attention should be paid to inequalities between sub-groups within communities when analyzing changes in health inequality over time.
\end{abstract}

Keywords: Community, Health promotion, Outcome evaluation, SES, Health inequalities

\section{Introduction}

Systematic reviews on the effects of interventions on equity in the field of public health revealed disillusioning and unclear results $[1,2]$. Some interventions may reduce, or at least not increase health inequalities, if they are of greater benefit to disadvantaged (higher risk) groups. Such interventions often comprise regulatory measures to improve housing and working conditions as

* Correspondence: nickel@uke.de

University Medical Center Hamburg-Eppendorf, Institute of Medical Sociology, Martinistraße 52, D-20246 Hamburg, Germany well as economic incentives (e.g. free fruit and veg provision in schools, increase in tobacco tax) [1,3]. Generally, rather structural, population-related ("upstream") interventions show these effects. Conversely, a number of researchers have emphasized the danger that public health interventions may increase health inequalities. Where an intervention is of greater benefit to advantaged groups than to others, this can be the case. Typical examples are media campaigns and interventions, which aim at individual education and behavior ("downstream interventions") or selective risk groups $[4,5]$. 
However, reviews on the impact of these interventions are mixed, raising some concerns about their effects on health inequalities. The underlying socio-ecological framework remains a general theory with no specification of causal pathways, and thus neither identifies specific ways to intervene, nor provides supportive evidence for interventions to reduce inequalities $[6,7]$. There are two implications of these findings on reducing health inequalities: For one thing, a 'one-size-fits-all' intervention may not be enough, but a combination of multiple intervention strategies is required, such as individual or group education, including broader intervention strategies as environmental changes and policies. Secondly, interventions which are well-tailored for the needs of individuals or sub-groups within a target population may result in better outcomes that are more equitable [8].

In the field of multi-component ("complex") community-based health promotion interventions there are, to our knowledge, only two reviews from high-income countries which explicitly address inequalities in terms of socio-economic status (i.e. SES including income, occupational status, assets or education), rather than other equity factors such as gender or ethnicity $[9,10]$. These reviews focussing on physical activity and smoking behavior have revealed limited evidence for reducing health inequalities. Either there were no differences by SES (education/income; 2 primary studies), or no data was found [1]. Furthermore, a fundamental methodological problem arises in this context: It is possible that interventions improve the health of a population (defined by place of residence or other measures) overall, but do not reduce or widen inequalities in health between sub-groups within the population due to preferential uptake by the comparatively most advantaged $[11,12]$.

Thus, the effect on (in)equalities can be classified as follows:

- Intervention likely to reduce inequalities: the intervention preferentially improved health outcomes in people of lower SES.

- Intervention likely to widen inequalities: the intervention preferentially improved health outcomes in people of higher SES.

- Intervention which had no preferential impact by SES (this also includes interventions with an overall benefit but without an effect on health equity between SES sub-groups within a community).

The aim of this paper is to provide a systematic review in order to explore, whether multiple community-based health promotion interventions improve the health of a socially deprived population overall (areal level) and/or reduce inequalities between socio-economically defined sub-groups. Attention will also be paid to the dynamics underlying the observed intervention effects mentioned above, i.e. the inequality within a community may increase while at the same time population health remains constant or even decreases [11].

\section{Methods \\ Protocol}

We conducted a systematic review according to the PRIS MA-Equity 2012 extension guidelines for systematic reviews with a focus on health equity [13]. An additional checklist shows this in more detail [see Additional File 1].

\section{Search strategy}

The search was limited to articles published in English and German during the period January 1, 1999, to August 31,2019 . The reason for choosing this period of time is that earlier reviews mentioned above $[9,10]$ are focussed on specific topics and do not contain the more recent studies and newer health promotion strategies; in addition, the present review should complement our prior review on the effectiveness of community-based health promotion interventions in the last 20 years [14]. We searched PubMed and PsycINFO databases (advanced search: title/abstract) using the string "(health

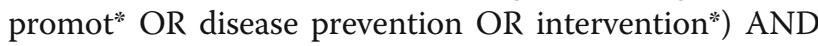
(neighbo\$rhood OR communit* OR area* OR district* OR ward* OR urban OR rural) AND (social determinant* OR occupation* OR education* OR socio* status OR income OR SES OR SEP OR social status OR equalit* OR inequalit* OR equit* OR inequit* OR disparit*) AND (effect* OR benefit* OR health outcome* OR impact* OR influence ${ }^{*}$ ) AND (randomi\$ed OR trial OR quasi-experiment* OR pretest OR posttest OR prepost OR time series OR controlled stud* OR before and after OR trend OR longitudinal) NOT (clinical OR review OR study protocol)". PubMed search resulted in 2563 hits, while PsycINFO came to 554 entries; after duplicates were removed 2876 records remained (see Fig. 1). In addition, all included primary studies from our previous review on the effectiveness of community-based interventions were searched [14].

\section{Selection criteria}

We included primary studies which evaluated the effectiveness of complex community-based health promotion interventions in high, middle and low income countries on any health outcome, and which reported differences in intervention effects between SES groups and/or socially deprived populations overall. Table 1 shows all inclusion and exclusion criteria to select eligible studies.

Studies included in the review should refer to the term "community" as a geographically defined area (e.g. neighbourhood, city, village), but not as a whole state or country. Further inclusion criteria were: peer-reviewed 


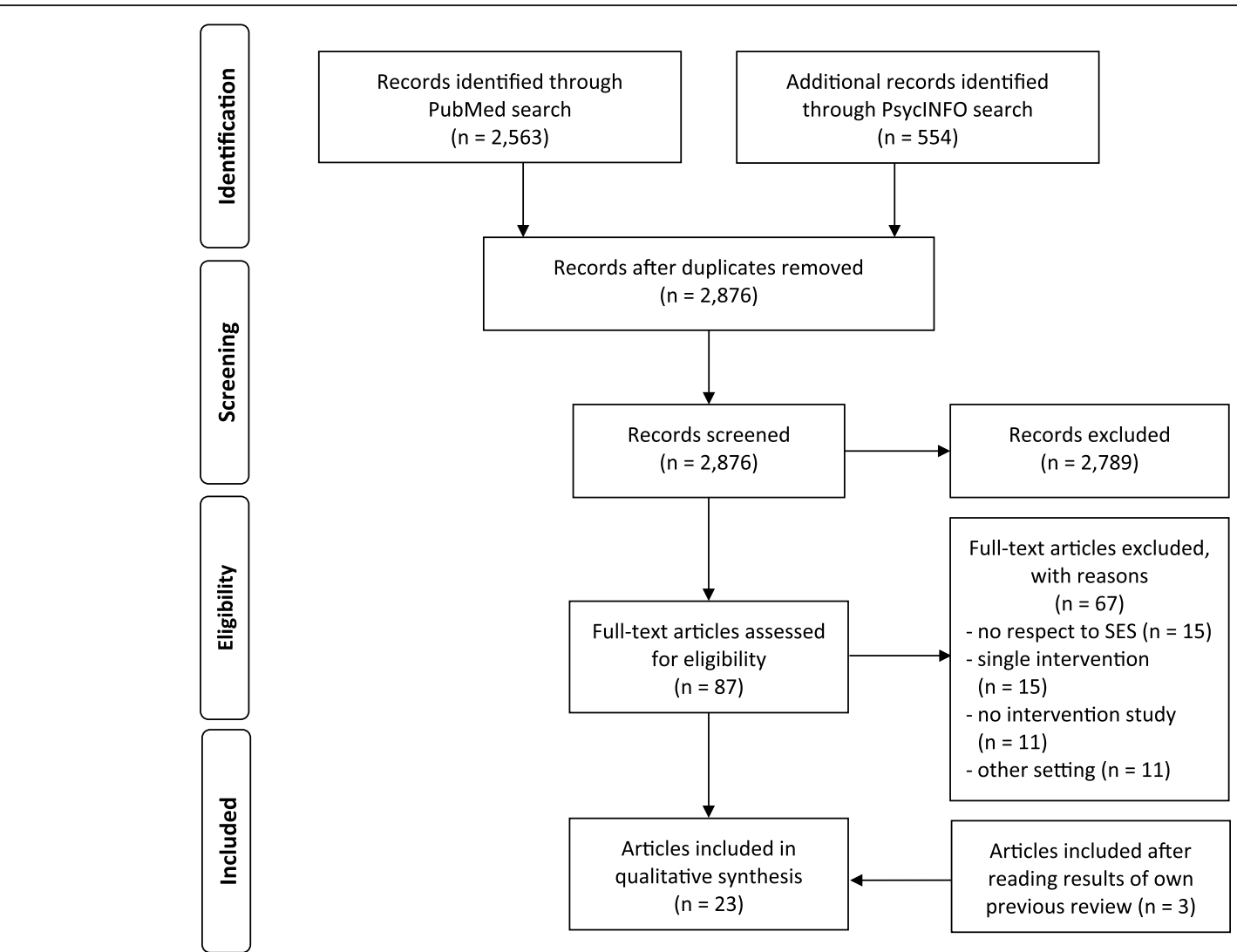

Fig. 1 PRISMA flow diagram

articles, intervention studies, assessment of one or more SES factors as well as multi-component strategies of intervention. The latter means that at least two different intervention types were provided, which also reflect social-ecological approaches of health promotion and prevention [7]. This includes changes based on the following six broad types of intervention: 1) social marketing (e.g. campaigns using mass media), 2) individual and group education (e.g. classroom instruction), 3) networking/partnership (e.g. advocacy groups), 4) environmental changes (e.g. greenspaces, availability of healthy food), 5) regulatory interventions (e.g. smoking policies), and 6) improving "sense of community" (e.g. neighborhood parties) $[9,15]$. In the literature, these

Table 1 Inclusion and exclusion criteria

\begin{tabular}{|c|c|}
\hline Inclusion & Exclusion \\
\hline \multicolumn{2}{|l|}{ Community } \\
\hline $\begin{array}{l}\text {,community'as geographic or political-administrative area } \\
\text { (e.g. neighborhood, residential area, district, city, village) }\end{array}$ & $\begin{array}{l}\text {,community'as ethnical group (e.g. migration background, religion) } \\
\text { or subcultural identity (e.g. gay community) without geographical } \\
\text { reference }\end{array}$ \\
\hline \multicolumn{2}{|l|}{ Article type } \\
\hline peer-reviewed original articles & editorials, reviews, articles on theory or study design, thesis \\
\hline \multicolumn{2}{|l|}{ Study type and research question } \\
\hline interventional studies (e.g. RCT, quasi-experimental study, pre-post-test) & observational studies (e.g. cross-sectional or case-control study) \\
\hline $\begin{array}{l}\text { research question on one or more SES factor (e.g. occupation, } \\
\text { education, income) }\end{array}$ & no research question on health inequalities according to SES factors \\
\hline \multicolumn{2}{|l|}{ Intervention } \\
\hline multiple interventions (two at least) & single interventions \\
\hline $\begin{array}{l}\text { interventions outside the healthcare system offered to people } \\
\text { without diagnosed illness }\end{array}$ & clinical treatments, palliative or rehabilitative interventions \\
\hline
\end{tabular}


interventions are understood to be interacting components that address different dimensions of complexity and mediating effects, e.g. regarding the outcome, target groups or stakeholders [6].

\section{Data extraction and synthesis}

Screening followed a two-step process with articles filtered by title/abstract, and full text. First author of this review (SN) initially screened the potentially relevant studies. The second author (OK) independently reviewed articles retained for inclusion in the preliminary phase. Full texts of the remaining 87 articles were read and checked by both authors for eligibility, of which 67 were excluded (see Fig. 1). If there were different views, a third colleague was asked to review the article in question (please see Acknowledgement), and a consensus was reached between the authors. Main reasons for exclusion were a missing consideration of SES, single intervention strategies, non-interventional study, and the focus on a non-community setting (e.g. school, workplace). Finally, we extracted data on characteristics of 23 included studies: author and publication date, study design, risk of bias, intervention types, outcome types, and the main findings on health inequalities.

Due to the heterogeneity of the included studies regarding methodological aspects (e.g. target populations, measurement instruments, statistical methods) as well as of the interventions and outcomes no meta-analysis was conducted. However, to identify trends and provide summary statements on intervention-generated inequalities, simple assessments were made for three possible findings by SES: increased inequalities, reduced inequalities, and no difference by SES. Ambivalent results include studies where there was an overall benefit for a disadvantaged population but no effect on health-related outcomes for any SES sub-group within population [8].

\section{Results}

\section{Description of the studies}

The twenty-three studies included in this review were conducted in high or upper-middle income countries (using the World Bank classification). Of these, 14 were set in Europe [16-29], five in North America [30-34], three in Australia/Oceania [35-37], and one study took place in a country in Central America [38] (see Table 2). The studies used various designs, including RCTs $(n=1)$ [38], cluster randomized trials $(n=3)$ [25, 30, 34], quasiexperimental designs $(n=11)[16,18,22,23,27-29,33$, $35-37]$, pre-post-tests without control group $(n=3)$ [17, $19,31]$, and secondary analyses $(n=5)[20,21,23,26$, 32]. The sample sizes at baseline varied from 200 to nearly 250,000 in 60 intervention areas, with study populations having a variety of socio-demographic and socioeconomic backgrounds. Few studies took place in what can be considered rural areas, while the majority of studies was located in urban neighborhoods, districts or cities.

With regard to the six types of interventions mentioned above, we found notable differences in the number and combination of these strategies. Sixteen articles explicitly emphasized the component of networking and partnership with local organizations (e.g. sport clubs) and volunteers. Other strategies were rather traditionally shaped, including some types of individual or group education (18 studies), social marketing (11 studies) and/or strategies to promote the "sense of community" (10 studies). Many studies used environmental change or regulatory strategies in specific settings (20 and 8 studies, respectively). Only one of the programs contained elements of all six strategies [16]. Six programs comprised five strategies [22, 23, 25-27, 32], five consisted of four $[21,23,25,28,37]$, six of three $[17,19,29,33,34,36]$ and five of two strategies [18, 20, 28, 30,36].

Twelve studies aimed at the improvement of health behavior (e.g. physical activity, F\&V intake, and smoking), eleven studies examined self-reported mental and physical health, and five studies additionally examined anthropometric outcomes.

\section{Risk of bias}

Included studies were assessed for risk of bias using the "Quality Assessment Tool for Quantitative Studies", developed by the Effective Public Health Practice Project (EPHPP) [39]. Studies were scored against six criteria (selection bias, study design, confounders, blinding, data collection method, withdrawals and drop-outs), and the number of weak ratings was summed up to give a global quality score. Of the 23 studies reviewed, ten studies were found to be of strong quality (43.8\%) [23, 25, 26, 27, 28, 30, 31, 34, 36 39]. Nine studies (39.1\%) were moderate in quality [16, 17, 19-21, 23, 32, 34, 37], and four studies $(17.4 \%)$ were weak in quality $[18,28,31$, 36]. $52.2 \%$ of all studies showed poor ratings or could not be evaluated regarding withdrawals and drop-outs. An additional file shows this in more detail [see Additional File 2].

\section{Impact on health inequality}

In the data extraction, we explicitly aimed to identify studies which were carried out in socially disadvantaged communities and/or conducted analyses of outcome measures by subgroups of SES such as income, education, and/or occupation. Out of the 23 studies that met our inclusion criteria, 13 (56.5\%) reported reductions of health inequalities in the entire (deprived) neighborhood or community [16, 17, 19-21, 25, 28-30, 32, 34, 35, 38]. However, this included one study in which there was little impact on health equity, but even more negative 


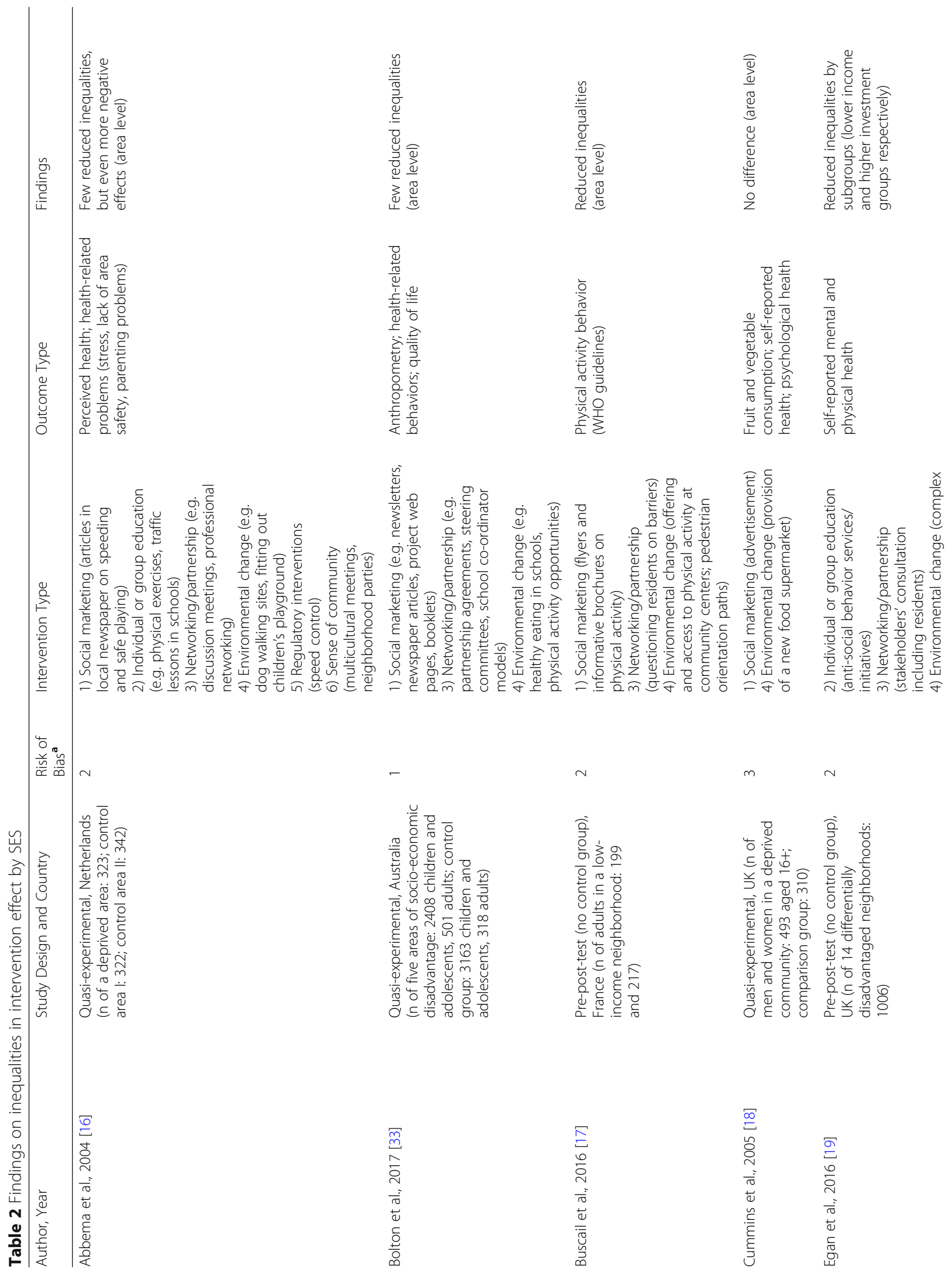




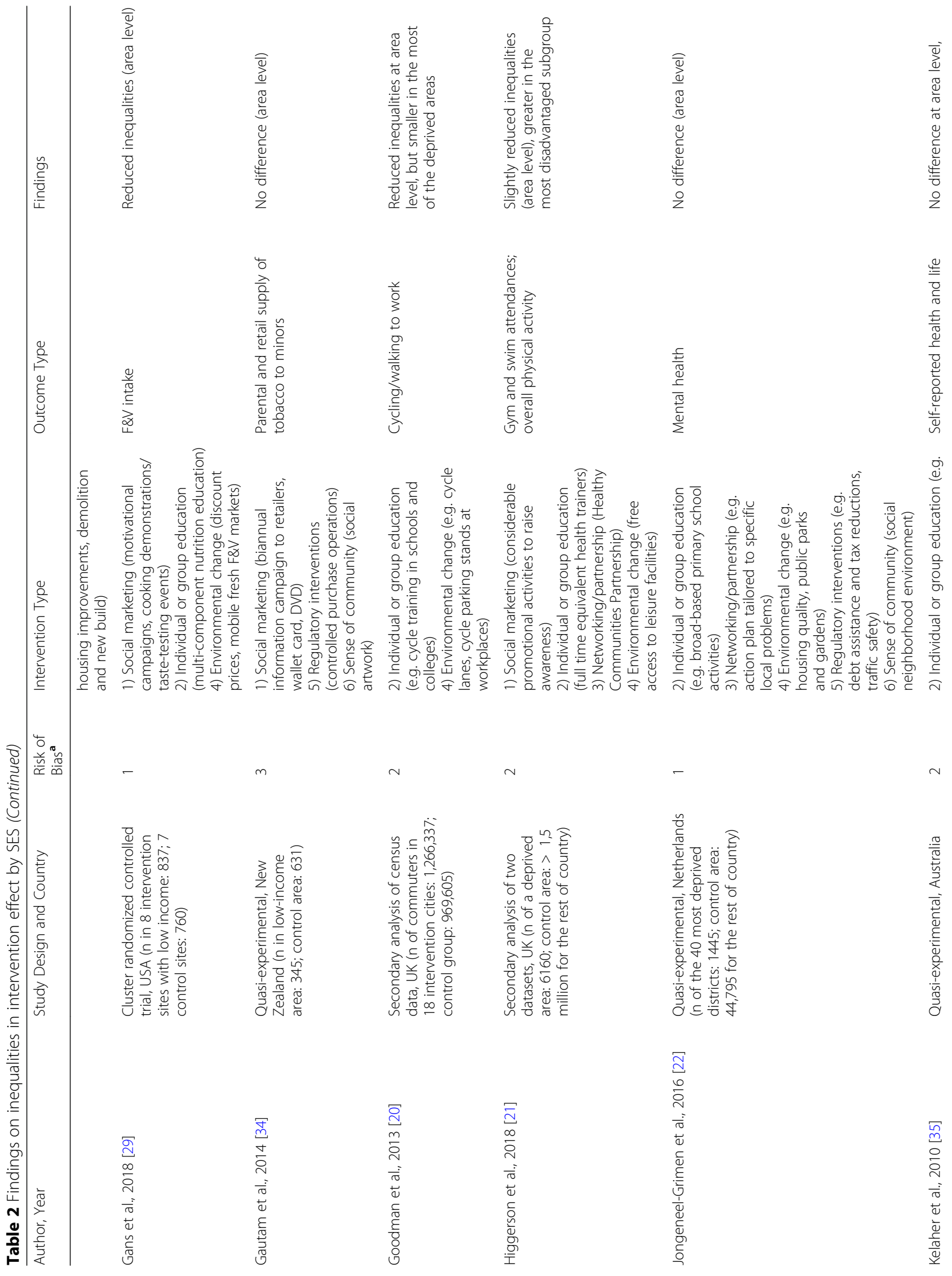




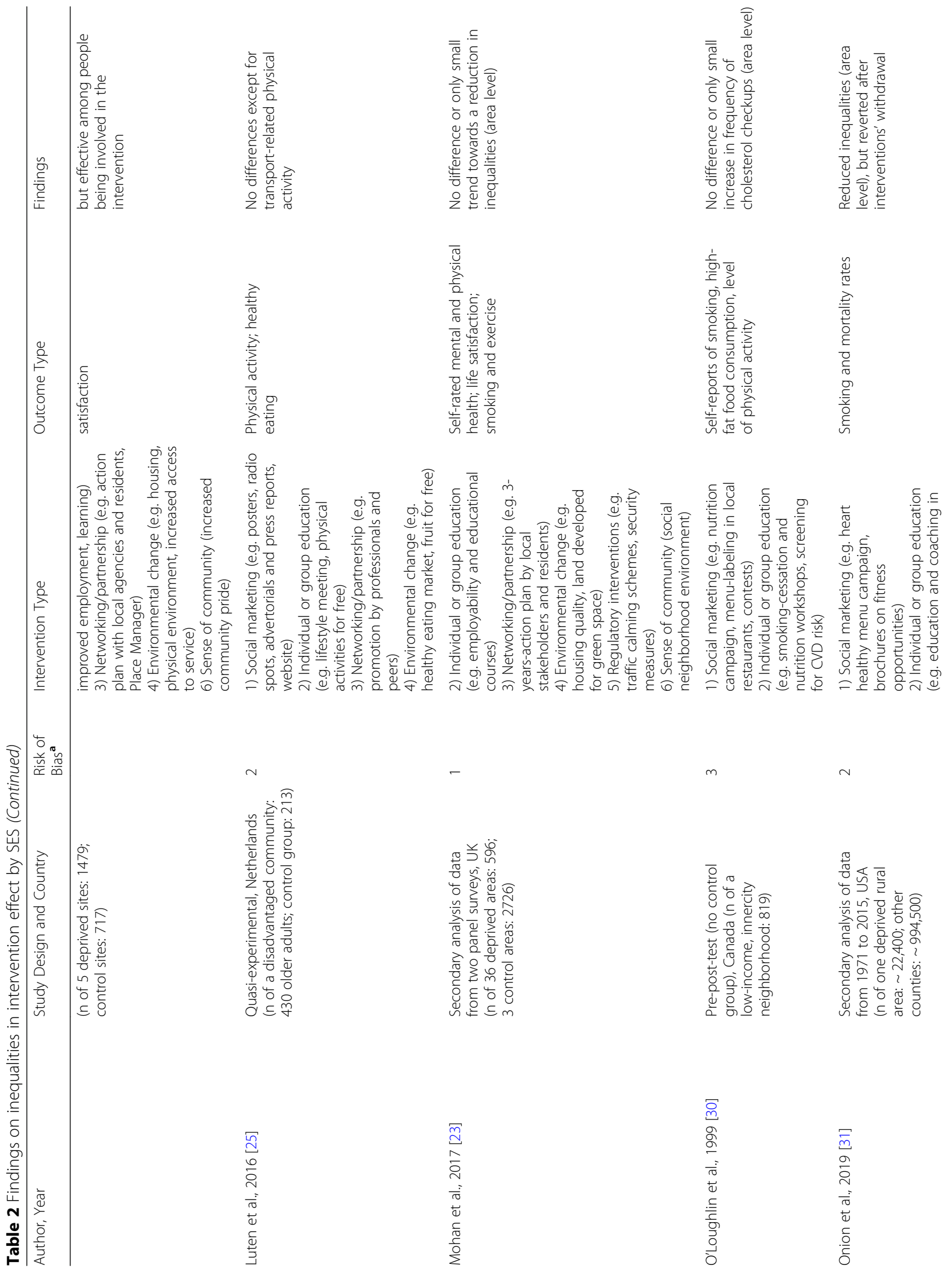




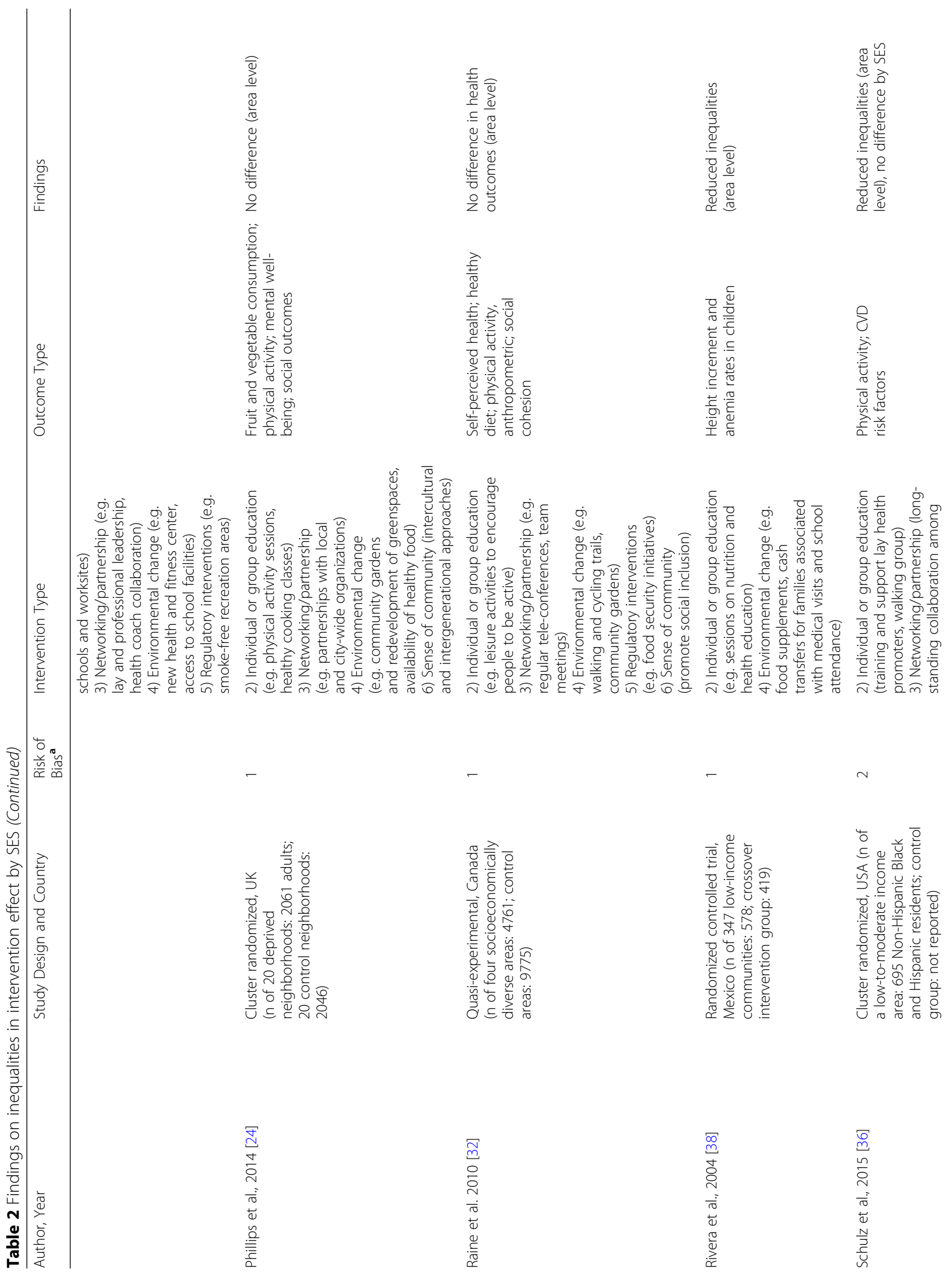




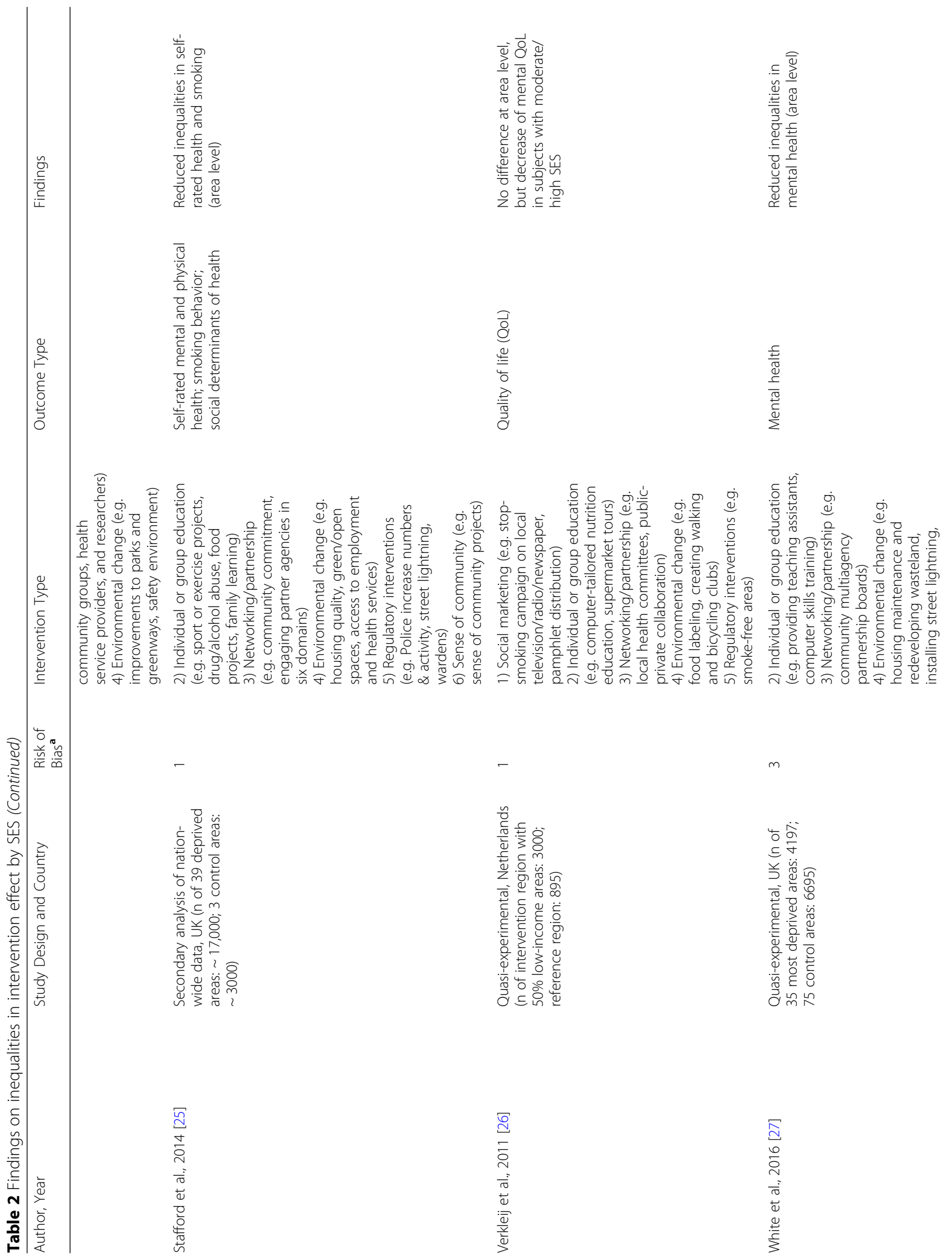




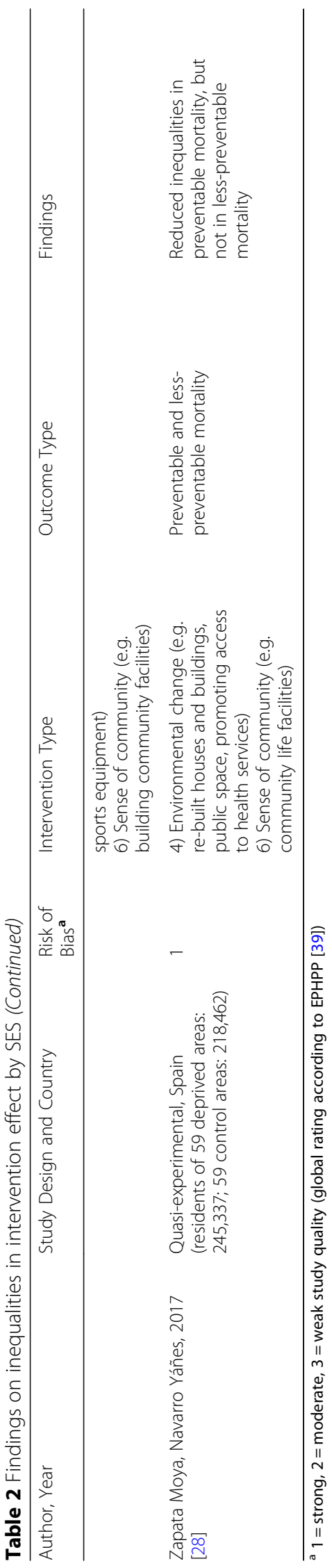


effects [16]. In two further studies (8.7\%), despite the lack of evidence at the level of the entire community, beneficial effects could be found in persons who belonged to the most disadvantaged subgroup within the area [27] or who were particularly exposed to the intervention [37].

Among the remaining eight (34.8\%) studies, no differences were found between intervention and control areas $[18,23-26,32,35]$. Only in one differential subanalysis a small intervention effect was found among those with a low educational level for energy intake and walking/bicycling [40]. No other studies except the two mentioned had analyzed the outcomes by socioeconomic subgroups within an area to search for a specific social gradient in health. These results seem to be rather sobering and inconsistent, involving both largescale (e.g. [25]) or smaller (e.g. [23]) programs with a very diverse mix of intervention strategies and outcome parameters. An important point in this context, however, is that there was, with one exception [16], no evidence that community-based programs included in our review resulted in any widening of health disparities ("intervention-generated inequalities" or IGIs) at community-wide level.

\section{Discussion}

Our review shows that complex community-based interventions can contribute to reducing socio-economic inequalities in health behavior and health status outcomes, or at least do not increase inequalities, respectively. The findings suggest that multi-level, multi-component interventions can be effective due to synergistic effects between multiple intervention components; besides this, complex interventions reside in the degree of flexibility or tailoring of the intervention permitted [41, 42]. Our results are also congruent with existing summaries of what is known about the effect of different categories of interventions on inequalities, particularly "upstream" interventions in the wider social (policy level) determinants: e.g. reducing price barriers, fiscal interventions, and housing $[1,3]$. Similarly, there is suggestive evidence that large, long-lasting urban renewal programs may positively affect physical and mental health, but the actual effects may be small $[28,29]$.

However, there was no consistent evidence to support the impact of such interventions in reducing the social health gap within an intervention population. To achieve an equity impact, healthy lifestyle interventions as well as activities to create a healthier environment need to be delivered in an adequate "dose" to stimulate or support health changes $[9,43]$. Thus, it has to be kept in mind that both the reach (significant proportion of the population being affected) and the intensity (frequency and duration of intervention components) of a neighborhood program are important. In many community intervention studies there is a high demand for process evaluation in order to assess the degree to which the intervention was implemented and met the dose as planned [41]. For example, we found some evidence for a dose-response association between length of residence in a regeneration area and a 'higher' level of investment during the study period, and improvements in mental and physical health respectively $[19,28,44]$.

White et al. described additional factors in the implementation of an intervention which may impact upon differential effectiveness by SES, including stages of the provision of, and responses to a health intervention [8]. Compliance may be higher among more advantaged groups due to better access to resources such as finance, time and coping skills. According to Roger's theory of diffusion, interventions may therefore (at different times) be more likely to be taken up by those persons who are of higher SES and are more likely to widen the health gap $[8,45]$. Conversely, the less educated or affluent groups are less able to access the intervention, understand it or engage in it. For this reason, interventions that are provided in the same way to all residents may result in differential outcomes. This is likely another characteristic of complex interventions that may widen inequality. Tailoring interventions need new ways especially for low socio-economic groups [46, 47].

Many community-based programs reviewed here relied on participation as a means of community involvement in the program planning and implementation. Thus, intervention-generated inequalities could have taken place, for example, when a community survey is used to assess the need for intervention. Socio-economic variations in response rates may lead to underestimation of need in the most socially disadvantaged groups [48]. Similarly, low SES groups are often less well represented in follow-up studies, leading to an attrition bias in the assessment of outcomes [49]. To address imbalances in power between socio-economic groups, the interventions need flexibility to ensure that they will be suited to the needs and perceptions of specific sub-groups, thus increasing participation and intervention effectiveness [41]. More community involvement increases the amount of time needed for intervention planning and implementation, and may have implications for the cost of such studies. In the long term, however, application of these methods is likely to contribute to improved intervention effectiveness and equity $[41,50]$.

\section{Limitations of the review}

There are a number of limitations concerning the present review. Initial searches of databases identified several thousand references, but the small number of eligible studies suggests that few health outcome 
evaluations of complex community-based interventions have been published in peer-reviewed journals in the last 20 years. Thus, the review described here is possibly not exhaustive and does not cover studies from low income countries. Our search strategy may not have revealed a complete list of all studies describing intervention effects by SES due to limitations of the Pubmed and PsycINFO databases. Single interventions and/or sub-settings (e.g. school, kindergarten) were excluded. Finally, the vast majority of studies identified targeted on effects at a low-SES population level, and did not explore differential effects on inequalities by SES sub-groups.

\section{Conclusions}

Despite the limitations described above, our review suggests that multiple community-based interventions in health promotion and prevention may contribute to reducing inequalities at area level, but their potential is not fully realized. Thus, based on this review, no final recommendations can be made for national policies. However, there are national and international initiatives that support the notion that health inequalities can be reduced by such interventions. For example, the German cooperation-network "Equity in Health" [51] mentions the community as an important setting for health promotion and defines criteria for good practice of community-based health promotion activities. There are similar initiatives in Europe highlighting the importance of complex health promotion interventions on the community level to reduce health inequalities [52]. Further studies should examine in more detail whether there is a change of health inequalities within an intervention area which affects the overall change in population health. Likewise, the results highlight the importance of including at least some measures of process evaluation in order to appropriately assess the benefits of these interventions on equity in health.

\section{Acknowledgements}

We thank David Cebulla for his support in reviewing articles.

\section{Authors' contributions}

SN and OK screened titles/abstracts to identify relevant publications and extracted the data. SN prepared the first draft. All authors are responsible for revisions and approval to submit manuscript.

\section{Funding}

This work was supported by the Free and Hanseatic City of Hamburg, Germany [grant number: LFF-FV 50]. Open Access funding enabled and organized by Projekt DEAL.

\section{Availability of data and materials \\ Not applicable.}

Ethics approval and consent to participate

Not applicable.

\section{Consent for publication}

Not applicable.

\section{Competing interests}

The authors declare that they have no competing interests.

Received: 15 January 2020 Accepted: 25 August 2020

Published online: 10 September 2020

\section{References}

1. Lorenc $T$, Petticrew $M$, Welch $V$, et al. What types of interventions generate inequalities? Evidence from systematic reviews. J Epidemiol Community Health. 2013;67:190-3.

2. Welch $V$, Tugwell $P$, Petticrew $M$, et al. How effects on health equity are assessed in systematic reviews of interventions (review). Cochrane Database Syst Rev. 2010;12. https://doi.org/10.1002/14651858.MR000028.pub2.

3. Bambra C, Gibson M, Sowden A, et al. Tackling the wider social determinants of health and health inequalities: evidence from systematic reviews. J Epidemiol Community Health. 2010;64:284e291. https://doi.org/10. 1136/jech.2008.082743.

4. Niederdeppe J, Kuang X, Crock B, et al. Media campaigns to promote smoking cessation among socioeconomically disadvantaged populations: what do we know, what do we need to learn, and what should we do now? Soc Sci Med. 2008;67(9):1343-55.

5. Capewell S, Graham H. Will cardiovascular disease prevention widen health inequalities. PLoS Med. 2010;7(8):e1000320. https://doi.org/10.1371/journal. pmed. 1000320

6. Craig P, Deppe P, Macintyr S, et al. Developing and evaluating complex interventions: the new Medical Research Council guidance. Br Med J. 2008; 337:a1655. https://doi.org/10.1136/bmj.a1655.

7. Golden SD, Earp JAL. Social ecological approaches to individuals and their contexts: twenty years of health education \& behavior health promotion interventions. Health Educ Behav. 2012:39(3):364-72.

8. White M, Adams J, Heywood P. How and why do interventions that increase health overall widen inequalities within populations? In: Babones S, editor. Health, inequality and society. Bristol: Policy Press; 2009. p. 64-81.

9. Baker PRA, Francis DP, Soares J, et al. Community wide interventions for increasing physical activity. Cochrane Database Syst Rev. 2015;1. https://doi. org/10.1002/14651858.CD008366.pub3.

10. Ogilvie D, Petticrew M. Reducing social inequalities in smoking: can evidence inform policy? A pilot study. Tob Control. 2004;13:129-31.

11. Mechanic D. Disadvantage, inequality, and social policy. Health Aff. 2002; 21(2):48-59.

12. Tugwell P, de Savigny D, Hawker G, Robinson V. Applying clinical epidemiological methods to health equity: the equity effectiveness loop. $\mathrm{Br}$ Med J. 2006:332:358-61.

13. Welch V, Petticrew M, Tugwell P, Moher D, O'Neill J, Waters E, et al. PRIS MAequity 2012 extension: reporting guidelines for systematic reviews with a focus on health equity. PLoS Med. 2012:9:001333.

14. Nickel S, von dem Knesebeck O. Effectiveness of community-based health promotion interventions in urban areas: a systematic review. J Community Health. 2019. https://doi.org/10.1007/s10900-019-00733-7.

15. Baker EA, Brownson CA. Defining characteristics of community-based health promotion programs. J Public Health Manage Pract. 1998;4(2):1-9.

16. Abbema EA, van Assema P, Kok GJ, de Leeuw E, de Vries NK. Effect evaluation of a comprehensive community intervention aimed at reducing socioeconomic health inequalities in the Netherlands. Health Promot Int. 2004;19(2):141-56

17. Buscail C, Menai M, Salanave C, Daval P, Painsecq M, Lombrail P, et al. Promoting physical activity in a low-income neighborhood of the Paris suburb of Saint-Denis: effects of a community-based intervention to increase physical activity. BMC Public Health. 2016;16:667. https://doi.org/10. 1186/s12889-016-3360-y.

18. Cummins S, Petticrew M, Higgins C, Findlay A, Sparks L. Large scale food retailing as an intervention for diet and health: quasi-experimental evaluation of a natural experiment. J Epidemiol Community Health. 2005;59: 1035-40.

19. Egan M, Kearns A, Katikireddi SV, Curl A, Lawson K, Tannahill C. Proportionate universalism in practice? A quasi-experimental study (GoWell) of a UK neighbourhood renewal programme's impact on health inequalities. Soc Sci Med. 2016:152:41-9.

20. Goodman A, Panter J, Sharp SJ, Ogilvie D. Effectiveness and equity impacts of town-wide cycling initiatives in England: a longitudinal, controlled natural experimental study. Soc Sci Med. 2013;97:228-37. 
21. Higgerson J, Halliday E, Ortiz-Nunez A, Brown R, Barr B. Impact of free access to leisure facilities and community outreach on inequalities in physical activity: a quasi-experimental study. J Epidemiol Community Health. 2018:72:252-8.

22. Jongeneel-Grimen B, Droomers M, Kramer D, Bruggink J-W, van Oers H, Kunst $A E_{\text {, }}$ et al. Impact of a Dutch urban regeneration programme on mental health trends: a quasi-experimental study. J Epidemiol Community Health. 2016;70:967-73.

23. Luten KA, Reijneveld SA, Dijkstra A, de Winter AF. Reach and effectiveness of an integrated community-based intervention on physical activity and healthy eating of older adults in a socioeconomically disadvantaged community. Health Educ Res. 2016;31(1):98-106.

24. Mohan $\mathrm{G}$, Longo A, Kee F. Evaluation of the health impact of an urban regeneration policy: neighbourhood renewal in Northern Ireland. J Epidemiol Community Health. 2017;71:919-27.

25. Phillips G, Bottomley C, Schmidt E, Tobi P, Lais S, Yu G, et al. Well London Phase-1: results among adults of a cluster-randomised trial of a community engagement approach to improving health behaviours and mental wellbeing in deprived inner-city neighbourhoods. J Epidemiol Community Health. 2014;68:606-14.

26. Stafford M, Badland H, Nazroo J, Halliday E, Walthery P, Povall S, et al. Evaluating the health inequalities impact of area-based initiatives across the socioeconomic spectrum: a controlled intervention study of the new Deal for communities, 2002-2008. J Epidemiol Community Health. 2014;68:979-86.

27. Verkleij SPJ, Adriaanse MC, WMM V, Ruland EC, GCW W-V, Schuit AJ. Fiveyear effect of community-based intervention Hartslag Limburg on quality of life: a longitudinal cohort study. Health Qual Life Outcomes. 2011;9:11. https://doi.org/10.1186/1477-7525-9-11.

28. White J, Greene G, Farewell D, Dunstan F, Rodgers S, Lyons RA, et al. Improving mental health through the regeneration of deprived neighborhoods: a natural experiment. Am J Epidemiol. 2016;186(4):473-80

29. Zapata Moya AR, Navarro Yáñez CJ. Impact of area regeneration policies: performing integral interventions, changing opportunity structures and reducing health inequalities. Epidemiol Community Health. 2017;71:239-47.

30. Gans KM, Risca PM, Kaita AD, Dionne L, Mello J, Stowers KS, et al. Multilevel approaches to increase fruit and vegetable intake in low-income housing communities: final results of the 'live well, Viva Bien' cluster-randomized trial. Int J Behav Nutr Phys Act. 2018;15:80. https://doi.org/10.1186/s12966-018-0704-2.

31. O'Loughlin JL, Paradis G, Gray-Donald K, Renaud L. The impact of a community-based heart disease prevention program in a low-income, inner-city neighborhood. Am J Public Health. 1999;89(12):1819-26.

32. Onion DK, Prior RE, Record NB, Record SS, Cayer GR, Amos Cl, et al. Assessment of mortality and smoking rates before and after reduction in community-wide prevention programs in rural Maine. JAMA Netw Open. 2019;2(6):e195877. https://doi.org/10.1001/jamanetworkopen.2019.5877.

33. Raine KD, Plotnikoff R, Schopflocher D, Lytvyak E, Nykiforuk CIJ, Storey K, et al. Healthy Alberta communities: impact of a three-year communitybased obesity and chronic disease prevention intervention. Prev Med. 2013; 57:955-62.

34. Schulz AJ, Israel BA, Mentz GB, Bernal C, Caver, DeMajo R, et al. Effectiveness of a walking group intervention to promote physical activity and cardiovascular health in predominantly non-Hispanic black and Hispanic urban neighborhoods: findings from the Walk Your Heart to Health intervention. Health Educ Behav. 2015;42(3):380-92.

35. Bolton KA, Kremer P, Gibbs L, Waters E, Swinburn B, de Silva A. The outcomes of health-promoting communities: being active eating well initiative - a community-based obesity prevention intervention in Victoria, Australia. Int J Obes. 2017:41(7):1080-90.

36. Gautam J, Glover M, Scragg R, Bullen C, Gentles D, Nosa V. Parental and retail supply of tobacco to minors: findings from a community-based social supply intervention study. Health Policy. 2014;117:120-7.

37. Kelaher M, Warr DJ, Tacticos T. Evaluating health impacts: results from the neighbourhood renewal strategy in Victoria, Australia. Health Place. 2010; 16(5):861-57.

38. Rivera JA, Sotres-Alvarez D, Habicht JP, Shamah T, Villalpando S. Impact of the Mexican program for education, health, and nutrition (Progresa) on rates of growth and anemia in infants and young children: a randomized effectiveness study. JAMA. 2004:291(21):2563-70.

39. Effective Public Health Practice Project. Quality Assessment tool for quantitative studies. Hamilton, ON; 1998. Available from: https://merst.ca/ ephpp. Accessed 10 Sep 1999.
40. Wanda Wendel-Vos GC, Dutman AE, Monique Verschuren WM, Ronckers ET, Ament A, van Assema P, et al. Lifestyle factors of a five-year communityintervention program: the Hartslag Limburg intervention. Am J Prev Med. 2009:37(1):50-6.

41. Sorensen G, Emmons K, Hunt MK, Johnston D. Implications of the results of community intervention trials. Annu Rev Public Health. 1998;19:379-416.

42. Craig P, Dieppe P, Macintyre S, Michie S. Nazareth Irwin, Petticrew M. developing and evaluating complex interventions: the new Medical Research Council guidance. Britisch Med J. 2008;337(25):979-83.

43. Trude ACB, Kharmats AY, Jones-Smith JC, Gittelsohn J. Exposure to a multilevel multi-component childhood obesity prevention communityrandomized controlled trial: patterns, determinants, and implications. Trials. 2018;19(1):287. https://doi.org/10.1186/s13063-018-2663y.

44. Thompson $\mathrm{H}$, Atkinson $\mathrm{R}$, Petticrew $\mathrm{M}$, et al. Do urban regeneration programmes improve public health and reduce health inequalities? A synthesis of the evidence from UK policy and practice (1980-2004). J Epidemiol Community Health. 2006;60:108-15.

45. Wejnert B. Integrating models of diffusion of innovations: a conceptual framework. Annu Rev Sociol. 2002:28:297-326.

46. Ashworth P. Breakthrough or bandwagon? Are interventions tailored to stage of change more effective that non-staged interventions? Health Educ J. 1997;56:166-74

47. Adams J, White M. Are the stages of change socio-economically patterned: a scoping review. Am J Health Promot. 2007;21(4):237-47.

48. Turrell G, Patterson C, Oldenburg B, Gould T, Roy MA. The socio-economic patterning of survey participation and non-response error in a multilevel study of food purchasing behaviour: areas and individual-level characteristics. Public Health Nutr. 2002;6(2):181-9.

49. Baquet CR, Commiskey P, Daniel Mullins C, Mishra SI. Recruitment and participation in clinical trials: socio-demographic, rural/urban, and health care access predictors. Cancer Detect Prev. 2006;30:24-33.

50. Cyril S, Smith BJ, Possamai-Inesedy A, Renzaho AM. Exploring the role of community engagement in improving the health of disadvantaged populations: a systematic review. Glob Health Action. 2015;8:29842. https:// doi.org/10.3402/gha.v8.29842.

51. Mielck A, Kilian H, Lehmann F, Richter-Kornweitz A, Kaba-Schönstein L. German cooperation-network 'equity in health' - health promotion in settings. Health Promot Int. 2018;33(2):318-24.

52. European Commission (ed.). Health inequalities in the EU - Final report of a consortium. Brussels: Consortium lead: Sir Michael Marmot; 2013. Available online: https://ec.europa.eu/health/sites/health/files/social_determinants/ docs/healthinequalitiesineu_2013_en.pdf.

\section{Publisher's Note}

Springer Nature remains neutral with regard to jurisdictional claims in published maps and institutional affiliations.
Ready to submit your research? Choose BMC and benefit from:
- fast, convenient online submission
- thorough peer review by experienced researchers in your field
- rapid publication on acceptance
- support for research data, including large and complex data types
- gold Open Access which fosters wider collaboration and increased citations
- maximum visibility for your research: over $100 \mathrm{M}$ website views per year
At BMC, research is always in progress.
Learn more biomedcentral.com/submissions 